\title{
THE EXPECTATIONS OF VOLUNTEERS PRIOR TO THE XVII COMMONWEALTH GAMES, 2002: A QUALITATIVE STUDY
}

\author{
RITA RALSTON,* PAUL DOWNWARD, $\dagger$ and LES LUMSDON $\ddagger$ \\ *International Centre for Research and Consultancy, Manchester Metropolitan University \\ $\dagger$ Business School, Staffordshire University \\ $\ddagger$ Department of Tourism and Leisure Management, University of Central Lancashire
}

\begin{abstract}
The XVII Commonwealth Games in Manchester, from July 25 to August 4, 2002, was the largest Commonwealth Games (the Games) and multisporting event ever held in the UK and required the recruitment and training of the largest volunteer workforce in the UK in recent decades. While much has been written about volunteering within different contextual backgrounds, and in relation to large-scale events, little research has addressed the issue of expectations of volunteers and their attitude towards functional management during the run up to a major international event. Using a qualitative research approach with focus groups this study addresses these issues. In terms of expectations, a number of key factors were identified in relation to the recruitment, training, and other management dimensions of the Games that have implications for volunteer motivation, responses to the psychological contract, and the long-term impact of a major event.
\end{abstract}

Key words: Volunteering; Volunteer expectations; Sport event; Commonwealth Games; Focus group

While much has been written about volunteering within different contextual backgrounds, and in relation to large-scale events, little research has addressed the issue of expectations of volunteers during the run up to a major international event. The XVII Commonwealth Games in Manchester, from July 25 to August 4, 2002, was the largest Commonwealth Games (the Games) and multisporting event ever held in the UK. Manchester welcomed 72 participating nations, over 5250 athletes and officials (including over 200 elite athletes with a disability), 1000 technical officials, 4500 media workers, and more than 1 million spectators. The
Games included over 1500 hours of competition, events, and ceremonies, broadcast to 110 territories across the world to an estimated television audience of 1 billion.

In addition to the estimated 6100 direct full-time equivalent jobs that it is estimated to have created, the Games recruited and trained the largest volunteer workforce in the UK in recent decades within this context. The significance of volunteers to the scale, reach, quality, and continuous development of major international sports events is only beginning to be recognized (Hollway, 2001; MacAloon, 2000). The financial success of the Olympic Games in Los Angeles in 1984, 
plus experience from sporting events in the 1990s and in particular the Olympic Games in Sydney 2000, illustrated the importance of volunteers in the delivery of this type of international event (Chalip, 2000; Gratton, Dobson, \& Shibley, 2000). Manchester 2002 Ltd had the responsibility for recruiting, selecting, training, and managing the volunteers; when they launched their recruitment campaign "Count Yourself In" during May 2001, over 22,000 members of the general public applied to become a volunteer. Approximately 10,500 unpaid volunteers were recruited from the general public and sports volunteering community to help with the delivery of the Games.

This article examines the expectations of those volunteers before the Games commenced. While expectations have been researched in different contexts, much of the work has been undertaken primarily in relation to consumer marketing where prepurchase beliefs about a product or service are compared with actual performance (Gronroos, 1982; Zeithaml, Berry, \& Parasuraman, 1988). Expectations are therefore seen to represent standards, or levels of satisfaction or dissatisfaction against which a person compares subsequent experiences. Thus, in this context, the authors define expectations as estimations or predictions of what working at an event will be like based on the experiences of recruitment, training, and communication prior to the event. In the case of volunteers, the complexity of reasons that motivate and encourage participation in this type of event are discussed, as are a number of other factors that might affect overall expectations about the likely outcomes of being involved in the actual event. The extent to which these prior expectations are met during the event will impact on the volunteers' satisfaction with and enjoyment of their volunteering experience, along with their perception of the overall success of the event. This in turn may impact on their continuance as a volunteer and their propensity to volunteer again for future events. As a substantial number of volunteers are recruited from the event's destination community and wider general public, they could therefore be regarded as "event ambassadors" and "future recruiters." Consequently, an appreciation of volunteers' expectations has a number of implications for planners of mega-events that make use of a large volunteer force. Thus, the aim of the study is to address a number of these issues. The article is divided into four sections. First, a summary of a literature review is presented to inform the research design. The second section refers to the research method and the third section highlights the key findings from the focus groups. The final section discusses the implications of the findings for managers of events.

\section{Literature Review}

A wider literature on the profile of volunteers and the nature of volunteering, including The 1997 National Survey of Volunteering, provides much background detail on wide-ranging aspects, such as participation and employability dimensions (Davis Smith, 1998; Hirst, 2000). Within the tourism literature, most studies relate either to volunteers and the maintenance of recreational tourism facilities (Caldwell \& Andereck, 1994; Goodlad \& McIvor, 1998; Heindrich, 1990; Holmes, 1999; Kay, 1997; Lord \& Lord, 1997; Mattingly, 1984; Smith, 2002) or to major hallmark events (J. A. Burns \& Mules, 1986; Mules \& Faulkner, 1996; Richie \& Aitken, 1984) However, many of these have not specifically addressed event preplanning of volunteer recruitment, composition, and expectations in relation to the successful management of an event.

The reasons why people volunteer are well documented. They form a mixture of altruistic, socialaffiliative, and instrumental reasons (Anderson \& Moore, 1978; Clary \& Snyder, 1999, 2000; Clary et al., 1998; Farmer \& Fedor, 1999; Heindrich, 1990; Miller, 1985; Pearce, 1993; Unger, 1991; Wardell, Lishman \& Whalley, 2000). L. Burns (2000) has extended the work by suggesting seven models of volunteering as an underlying basis of an ongoing development of volunteering. These models comprise: philanthropic and social giving; mutual aid and selfhelp; community activist; campaigning; protesting; government programs; and the personal development model. She argues that recognizing the range of models and approaches presents a challenge for those organizations facing the need for effectively managing a diverse volunteer workforce.

The literature also reports a range of demographic variables such as gender and age differences. For example, there is a tendency that men have to be asked to volunteer, primarily in response to their own needs and interests, or because of the social benefits associated with volunteering. In contrast, women are more likely to offer to help, in response to the perceived needs of family and friends. Age is another important variable. Older people report that they have more time to spare 
and want to meet new friends, whereas younger people recognize that volunteering provides an opportunity to develop new skills (Davis Smith, 1998).

There are also a number of documented barriers to volunteering. Many people would like to become more actively involved in volunteering but lack time. Other studies cite the issue of not knowing any other volunteers or declining on the basis of not having the necessary skills and experience. Davis Smith (1998) suggests that there are a number of ways in which people can be encouraged to volunteer: being asked; help to get started; family and friends' involvement and support; opportunity for skills and qualification improvement; and being able to engage in volunteering from home. These factors have implications for the recruitment and retention of all volunteers but are particularly relevant for those organizations that need to recruit substantial numbers of volunteers, even for relatively short finite periods of time, from the general public.

Within many recreational activities and major events, volunteerism tends to be sporadic and episodic and is highly dependent on the availability of tangible and intangible incentives and awards to attract and motivate volunteers. A feeling of "connectedness" with something special by belonging to and sharing in the event is often the main reason why many people volunteer from the local and wider community (Getz, 1989). Other factors that influence volunteer motivation for major events have been identified (Moragas, Morena, \& Paniagua, 2000; Williams \& Harrison, 1988):

- volunteers' perception of the "spirit" or philosophy underpinning the event;

- volunteers' commitment as local and national citizens;

- how the event supports the development and image of the local community, region, and nation;

- the tangible and intangible rewards and opportunities that the event offers;

- volunteers' expectations of the experience itself.

There are a number of specific studies that support this general overview. Motivations of volunteers at the Men's Whistler World Cup of Skiing varied between Whistler residents and nonresidents. The residents' main motivations included the chance to build community image and spirit as well as supporting the National team. For nonresidents, the opportunity to socialize with people who shared common interests and enthusiasm for skiing was seen as more important. Younger volunteers were significantly more interested in opportunities for personal and skills development. Tangible physical and economic rewards such as free tickets, job contacts, and souvenirs rated very low; however, they were slightly more important to younger and female volunteers (Williams, Dossa, \& Tompkins, 1995). Thus, there are clear expectations as to some of the core intangible and tangible benefits that might accrue from participation. As such, the generic expectancy theory of motivation, espoused by expectancy-based models such as those of Vroom (1964) and L. Porter and Lawler (1968), have relevance towards the complexities of motivating and managing volunteers at major events. These expected benefits have tended to be ranked as motivations parallel to the three-category typology of purposive, solidarity, and material incentives identified by Caldwell and Andereck (1994) in recreational organizations. Volunteer motivations at the Canadian Women's Curling Championship can be further grouped into four categories: purposive, solidarity, external traditions (extrinsic motivations), and commitments (expectations from others to volunteer) (Farrell, Johnston, $\&$ Twynam, 1998). To this extent event volunteer motivations are slightly different that other types of volunteers, and event managers need to be cognizant of this.

Having motivated someone to volunteer at an event, what else makes them feel satisfied? Event volunteer satisfaction is influenced by expectations prior to the event as well as actual experiences during the event, which includes the administration and management attributes that influence how effective the event itself is organized. Failure to match the requirements and expectations of the job with those of the volunteers will make the event's management even more challenging.

There is substantial research on the factors that typically influence volunteer satisfaction and retention levels (Bretell, 2000; Elstad, 1997, 2003; Farrell et al., 1998; Galindo-Kuhn \& Guzley, 2001; Getz, 1991; Gidron, 1983; Kemp, 2002; Nakajima, 2000; Ronningen, 2000; Smith, 2002; Williams et al., 1995). These are summarized in Table 1.

In theory, if event organizers and volunteer managers are aware of and address the issues of expectations and sources of satisfaction, as outlined above, problems and dissatisfaction should be minimized. In sum, expectations will be met and possibly exceeded. However, Getz (1997) points to the large, and often unique, 
Table 1

Volunteer Satisfaction Criteria

Work assignment (role assigned, job fit for both skills and convenience, empowerment).

Adequate and sufficient information to enable the volunteer to do their job, clarity, recognition, feedback, face to face.

Participation efficacy (task competency, intended result, benefits to others, importance of their role, and contribution to target population).

Organizational empathy with the volunteers and understanding the event from the volunteers' perspective.

Recognition that volunteers have other commitments.

Careful planning and scheduling of workloads, daily activities, tasks, and related event responsibilities.

Orientation, philosophical underpinning, and training.

Recognition of lack of previous or similar volunteering experience.

Quality of organizational support (training and emotional support, supportive environment, supportive supervisors, availability of help when needed).

Communication and organizational guidance and support systems.

Volunteer networks and informal support systems and activities.

Group integration (contact and social aspects of relationships with other volunteers and paid staff) as correlations with volunteer satisfaction and predictors of intent to remain.

Continuous encouragement, support, and recognition.

Specialized recognition and memorabilia.

No distinction within groups of volunteers and with other staff.

Relationships with supervisors, managers, other volunteers, paid staff, visitors, and the wider community.

Not being taken for granted.

Good supervision and sorting out problems early on, good volunteer management.

Physical facilities and event environment, food, toilets, and transport.

Access to formal event venues and an opportunity to be involved in special and more prestigious parts of the event (e.g., ceremonies).

number of stressors for event volunteers that are potential causes of "burn-out," resulting in diminished volunteer involvement. These include factors such as an intense time and energy commitment; overdemanding workloads; insufficient numbers of volunteers; tensions between volunteers, staff, and others; open public scrutiny; lack of effective leadership; absence of tangible rewards; insecurity over one's appointment or volunteer role; and boring or unfulfilling labor.

Dean (1985) identified three symptoms of volunteer "burn-out" as emotional exhaustion, depersonalization (reflected in the poor opinion of others), and feeling of reduced personal accomplishment (sometimes accompanied by depression and loss of self-esteem). The most deeply involved and highly committed volunteers are the ones most likely to burn out, and these feelings are often intensified towards the end of an event with the growing awareness that their volunteer role is coming to an end (Howell, 1986).

Although major sports event volunteers experience problems and feel dissatisfied, the opportunity to be involved in a unique event and the celebratory atmosphere may be more important to them than relinquishing the volunteer role. Volunteer dissatisfaction may not result in volunteer turnover, given the limited duration of most events; however, there are implications for the effectiveness of the volunteer and, if dissatisfaction is widespread, the volunteer resource as a whole. Understanding how volunteers perceive the strengths and weaknesses of the event prior to its execution can provide a sound foundation for strategies for maintaining volunteer support for the event and future events.

On the part of the volunteer, the literature refers to the need for volunteers to cope with time management as the lack of time availability increases potential temporal conflict, where it is often the volunteer role that suffers. Consequently, volunteers may choose to limit their involvement to an occasional basis or stop volunteering altogether (Farmer \& Fedor, 2001; Pearce, 1993). Unger (1991) found that dedicated volunteers often offer time at the expense of other activities; Pearce (1993) recognizes this as a well-known problem of volunteer management.

The appropriate management of the volunteer force is not only critical to their motivation, retention, and the level of hospitality they convey, but also to contributing to their perceived satisfaction with the volunteer experience and the event itself. It also has implications for the ability to develop a base of future volunteers in the community and to fully embrace the potential of volunteering as a contribution to the sustainable development of local communities (Smith, 2002).

Another dimension of the volunteer role has been discussed in terms of the "psychological contract." A 
psychological contract refers to a particular type of promissory contract that an individual "believes" is the basis of the terms and obligations of a reciprocal exchange between themselves and another party (Robinson \& Rouseau, 1994; Rouseau, 1989; Rouseau $\&$ Parks, 1993). These contracts are based on expectations, often formed by the initial "rhetoric" of the organization (Grant, 1999), and trust that these expectations will be met. Negation of these aspects constitutes a breach or violation, which often evokes an intense response because essentially a "promise" has been broken and therefore it is more personalized (Morrison \& Robinson, 1997; Rousseau, 1989, 1995). Citing earlier studies, Pate, Martin, and McGoldrick (2003) highlight the multifaceted consequences of psychological contract violation. These responses include: disappointment, frustration, and distress; anger, resentment, bitterness, indignation, and increased cynicism; reduced job satisfaction, organizational citizenship, commitment, attendance, and performance; all of which have an impact on attitude and behavior towards other organization members and external contacts, and may eventually result in noncontinuance (Coyle-Shapiro, 2002; Coyle-Shapiro \& Kessler, 2000; Pate \& Malone, 2000; Robinson \& Morrison, 1995; Rousseau, 1989).

Farmer and Fedor (1999) argue that it is important for volunteer management to give due recognition to this and to develop a supportive, two-way relationship throughout. They investigated the expectations of volunteers early in the process of recruitment, noting volunteer attitude, participation, and intention to withdraw. These expectations, experienced early in the process, included the extent to which volunteers felt valued, appreciated, and that the organization genuinely valued their efforts and well-being (e.g., in terms of providing resources, training, and management support).

Most general and event volunteer studies focus on the volunteer and the relationship between variables such as family background and the level of participation (e.g., as a way of understanding motivation). None of the studies have addressed the issue of how managers of events can be proactive and use the lead-in period of recruitment and training as a way to inspire volunteers with positive, albeit realistic, expectations regarding their entire experience during the event. In the employment arena the significance of the influence of experiences during the different stages of organization entry has been recognized for some time (M. Porter, 1980; Van Maanen \& Schein, 1979). More recent studies have reinforced the importance of the recruitment and orientation activities in the preentry anticipatory socialization stage in developing the subsequent relationship and desired behavior (Garavan \& Morley, 1997; Scolarios, Lockyer, \& Johnson, 2003).

In summary, the literature provides a framework for analysis of the motivation and expectations in relation to Commonwealth Games volunteers, many of whom were recruited from the general public, who may or may not have had previous experience of volunteering. Given that the duration, scale, and diversity of the utilization of volunteers in major sports events are different than the usual type of sports and general volunteers, how do their motivations and satisfaction compare? As well as the general intrinsic and extrinsic factors outlined in the previous section, studies of volunteers at sports and other events show that these motivations and expectations can be further refined. This forms the conceptual framework within which the qualitative analysis has been undertaken.

\section{Research Method}

The research task involved seeking detailed responses from volunteers about their expectations, especially with regard to management issues such as recruitment and training during the lead-time to the Games. In this context, it was decided that a qualitative research approach using the focus group technique would be appropriate given the nature of the study. There are a number of reasons leading to this decision. A review of the previous literature had discussed the key motivational factors as to why people volunteer in general. These tend to be similar and verified across a range of studies (Anderson \& Moore, 1978; L. Burns, 2000; Clary \& Snyder, 1999, 2000; Clary et al, 1998; Farmer \& Fedor, 1999; Heindrich, 1990; Miller, 1985; Pearce, 1993; Unger, 1991; Wardell et al., 2000;). However, it also illustrates that little research has actually conceptualized and operationalized expectations in a more specific enquiry. There are also findings in relation to major events that indicate a similar pattern of motivational behavior during or reported after an event, but once again the analysis of expectations in relation to engagement at an event is not addressed (Coyne \& Coyne, 2001; Farrell et al., 1998; Williams et al., 1995).

In contrast, there have been relatively few studies that have probed volunteers more specifically about their attitudes towards functional management (e.g., in 
relation to recruitment and training). Nor have there been many preevent studies published in the literature. Thus, the researchers had not identified or presupposed a theory based on the previously published material. Given this, an inductive, exploratory approach to the exploration of the subject area and collection of data was appropriate in this context (Blaikie, 2000). It was felt that the focus group technique would be suitable to generate constructs about expectations; it has been used extensively for this purpose in numerous studies. Thus, the research approach involved discussion groups focusing on the experiences of the participants, rather than a heavily prescriptive approach. This would enable the researchers to shape the direction of work and to reach a point of confirmation regarding more specific expectations about this type of international event.

The research benefits associated with the focus group approach are well documented in the literature (Frey \& Fontana, 1993; Kreuger, 1988, 1998). These include the potential to encourage a sharing of insights, the stimulation of interactive discussion that leads to either consensus or clearly defined disagreement. In sum, the approach can elicit "historical-hermeneutic and critical emancipatory forms of knowledge, developed in the research process by and for its subjects" (Goss, 1996, pp. 115-116). The research philosophy adopted in this exploratory piece of work, therefore, assumes that social phenomenon are socially constructed, relatively complex, and in need of interpretation through a qualitative research process (Strauss, 1987). Thus, the researchers held a view that the interactive nature of the focus group would unfold a more accurate picture of the social reality of the volunteer than a series of individual in-depth interviews or other similar qualitative research instruments.

However, there are other reasons why the focus group technique was adopted. The volunteer experience tends to be both interactive and collective in nature. Therefore, to utilize a research technique, which is in itself a social event, involving open discussion, as well as a degree of reflection and a convocation of deeper feelings, was considered to fit in this investigation (Goss, 1996). In actuality, several of the convened groups asked, without any prompting from the moderator, whether they could be reconvened after the Commonwealth Games in order to share experiences again at a later stage. One additional functional point relates to time constraints; a focus group can be assembled within a matter of weeks and this was necessary in the limited time available during the run up to the Games.
The limitations of this approach were also noted. For example, the focus group findings represent a very small number of volunteers. Secondly, in terms of analysis it is difficult to address the causal links between the reasons for volunteering and expectations with this type of technique. Nevertheless, given the exploratory nature of the study, the research approach was considered to be valid within the context of this particular event.

Seven focus groups were convened with 72 participants drawn from the North West of England, in the UK. The composition of four of these was by using gender and age variables [older females, older males, younger females, younger males] although categorization by younger/older was chosen arbitrarily at the age of 45 . Two other mixed groups were selected on the basis of respondents either having or not having previous volunteering experience. The final group was mixed gender, age, and experience. The selection process was undertaken in conjunction with the official recruitment and training organization, Manchester 2002 Volunteer Services. The volunteers were asked whether or not they were prepared to participate in a pre-Games study and given dates when focus groups would take place. This proved useful as it prompted respondents regarding availability. Each respondent also completed a form to provide information for further selection purposes including gender, age, previous volunteering experience, and place of residence. This basic information was used to arrange potential group members into the seven groups.

The groups were held in the meeting room of the Games Volunteers headquarters located in the central zone of Manchester. Each was moderated by one of the researchers (the female moderator attended four groups while the male moderator attended three groups). The role of the moderator is to encourage participants to guide the dialogue, insofar as addressing the key tasks raised by the researcher exercise, and to encourage everyone to participate in this dialogue (Greenbaum, 2000). In two meetings the coauthors observed the group meetings. In all cases, the moderators were accompanied by a research assistant, who taped and noted the proceedings, but did not take part in the discussion.

At the end of each focus group, of approximately 90-minute duration, the moderator(s) and the research assistant discussed the findings and possible interpretations. Following this, each transcript was interpreted independently by the researchers. The proceedings were 
recorded and analysis undertaken using a template formulated by Crabtree and Miller (1999). A coding system, which identified major issues, was therefore devised and the transcript material from each group was segmented into units of analysis on paper. A final meeting of the three researchers was undertaken, to discuss the analysis collectively, and to interpret the resumes of all of the focus groups as a whole. In this way it was possible to recall the group dynamics and flow of discussion so that the entire process or dialogue could be evaluated rather than simply relying entirely on a coding and retrieval system per se (Catterall \& Maclaran, 1997). This approach was adopted to improve validity and reliability of the final analysis of the transcripts (Holbrook, 1996).

\section{The Findings}

This section reports the findings of the focus groups and in relation to the literature review. Key common issues are as follows.

\section{Attitudes Towards Volunteering and Reasons for Participation}

Attitudes towards the concept of volunteering per se influence participation in volunteering activities. These attitudes and the reasons offered as to why people become involved can be seen as an early indication of expectations of the volunteering experience. The discussions commenced with a focus on why people volunteered in general and why they had volunteered for the Games in particular. The most important reason was that volunteering is a way of giving something back to society. In some cases this was expressed in terms of the local community and a desire to achieve a sense of involvement or belonging, or as one participant commented:

I personally feel that it's a thing that a lot of people desire these days but don't necessarily see because the family unit is changing. People move away from a local area so people haven't got an identity. . . . So I personally feel that things like this, and the other things I do, mean that people can meet rather than just stay behind the wall and not know who your neighbours are. (young male, employed, previous volunteering experience)

This view was common across groups and was associated with the idea of helping those less fortunate in life. On a more personal level, some participants sug- gested that volunteering was rewarding; it provided a "feel good" factor. Volunteering enabled them to help others, to enjoy new experiences, and in some circumstances to widen their horizons. It also provided an opportunity to meet other people; "I've got so many friends through scouting and its something different. It gives me another avenue" (young female, student, previous volunteering experience).

Some groups explored the different reasons volunteers might offer in relation to age. A group of older female participants was asked why they thought young people might volunteer. The response was that employability and the opportunity to improve the curriculum vitae might be more important for younger volunteers, but this would not be the case with older people. Another group considered that it might also be a matter of status. For the group of older females volunteering filled a gap in their lives either through a change of family or work circumstances. It was also a way of showing that an older person can still be very useful in society, a view that was echoed elsewhere by older participants.

Most people thought that voluntary work was something that they personally had to do; it was innate. It was part of their life. Others felt that family background was a key determinant. A few commented that they had been brought up in families where volunteering had always been part of their life. These two factors were by far the most important. Some groups also commented about the way in which volunteering is viewed by society. In general they felt that volunteering was not valued by society. Some even suggested that they rarely raised the topic with others as it was a subject of ridicule. Several respondents referred to an increasing level of materialism: "A lot of my friends say why are you doing it if you don't get paid, and I think how shallow is that. I'm doing it because I want to. They disagree with me and think I'm stupid" (young female, student, previous volunteering experience).

Nevertheless, they did not feel that the commercialization of sport or sponsorship was a major reason for this prevailing attitude. They felt that people were simply more skeptical about undertaking work on a voluntary basis and therefore were less likely to volunteer. Older participants felt that young people were less inclined now to help than their counterparts in previous decades. This, however, was not a view shared by all participants. Some of the younger respondents were less inclined to accept this argument and felt that volunteering was still appealing for young and old; the criti- 
cal factor was having the time available (e.g., in relation to pursuing a challenging career). One group commented that there was a reluctance to become involved because of a feeling of being taken for granted.

A group of older males discussed the process of gradual involvement in volunteering:

It comes as a necessity, doesn't it? If you are a member of an amateur organisation and they need somebody on the selection committee and that really is I think where it starts. . . I played cricket from a very early age and once you get into having been the Sunday B player, then the second team, then you get involved in the selection committee and it is an ongoing process. (older male, retired, previous volunteering experience)

\section{Level of Interest in Sport and Its Influence on Participation as a Games Volunteer}

Given the nature of the Games, participants were asked about their interest in sport and its impact on their decision to volunteer. The extent of their interest and "association" in the main purpose of the event could also be a factor that shaped their expectations. Their sporting interest was variable. For example, most of the group of younger females engaged in some form of sporting activity at least once a week. A significant minority was involved in competitive sport at club level. This was not common across groups and a variety of sports were pursued. Younger females were inclined to play hockey whereas men tended to be involved in football, rugby, table tennis, and badminton. Other groups reported interest in snooker, pool, rugby, and horse riding. In some cases people indicated that they had participated in sport in the past but more recently had since become involved in management or administration of a club (i.e., committee work). In a small number of cases this involved sports skill development such as instruction and coaching.

The groups were asked whether it was important to have an interest in sport to be a volunteer at the Games. Most people perceived the Games from an event perspective rather than sport perspective. Two factors were important: the uniqueness of the event and the international nature of the Games. However, for the older males sport was more of an important dimension. In sharp contrast some participants expressed little or no interest in sport. This was particularly noticeable amongst many of the older female participants: "I was never sporty. I hate sports although I could watch gymnastics or diving, I don't like sports that are a race to win" (older female, retired, no previous volunteering experience).

However, most participants enjoyed being regular spectators at football or cricket matches or more commonly that they watched sport on television, particularly football, cricket and golf, swimming, tennis, athletics, and gymnastics.

\section{Degree and Experience of Previous Volunteering Activities}

Expectations of current and future experience are shaped by previous experiences; therefore, the second area of discussion focused on the extent of their previous volunteering activity and the positive and negative aspects of this experience. The differences between those with volunteering experience and the others were explored even though most people had had some previous experience of volunteering. One group did not have any experience of volunteering but the views they expressed were similar to others. In general, there was a very wide range of volunteering activity undertaken, from helping in local schools and churches, to working for national charities. Several had volunteered for tasks at a sports club or sporting organizations. The exception was a group of older males, who had a considerable amount of experience in the sport sector, including two people who had been long-term Games volunteers. A small number of older males and female respondents in the mixed groups had also previously helped with sports clubs and societies.

The amount of time devoted to volunteering varied from very occasionally to a regular weekly commitment. Several participants indicated that they spent approximately 6 hours volunteering on average. For a significant minority volunteering was a way of life, especially those who were not working. They indicated that they spent 1 or 2 days per week undertaking volunteer tasks. In contrast, those who were working had little time to offer.

The participants were asked to comment about the positives and negatives of their previous experience. Several aspects were explained but in essence these related to a personal sense of achievement. This, in turn, was a consequence of being able to help others. The other main reason was being part of a team. One participant commented that it was about: "getting a buzz and a lot of personal satisfaction feeling that I' $m$ doing 
something to help, and meeting a lot of different people, yet all you're doing is being yourself" (older female, employed, previous volunteering experience).

The worst aspects focused on the level of commitment required. Some mentioned other reservations such as a lack of appreciation, poor organization, and volunteers not pulling together as a team: "You can feel slightly excluded where you're working with others who are getting paid. They forget to tell you what's going on. You feel sort of, not left out, but community excluded" (younger female, employed, previous volunteering experience).

Several experienced volunteers also indicated that it was difficult to relinquish posts of responsibility. Once a person has been recruited into the management structure of a voluntary organization it was difficult for them to release this type of role.

\section{Expectations of the Games}

The focus groups then discussed their expectations regarding the Games based on their experiences during the lead time to the event. They addressed aspects of communication, recruitment, and training. This started with a discussion about a major orientation event organized for volunteers in April 2002. Approximately 10,000 volunteers attended this evening of entertainment and rallying at an arena in a central zone of town. Not all focus group participants had attended. Those who had been at the event expressed mixed views. Some were disappointed with the focus of the evening as the invitation had described it as a training event and an opportunity to meet their team. Other than the distribution of the first part of the volunteers' handbook they felt there was no training element. As many volunteers had not been allocated a specific Games role by that stage, they did not have an opportunity to meet their team. Some had reservations about the style of presentation. They did not like the mantra and suggested that they felt uncomfortable with the level of audience participation and interaction approach to the event; this was seen as not entirely appropriate in the UK. Despite these criticisms, most participants eventually felt that it was a worthwhile experience; it widened horizons and delivered a clear message about the scale of the event to come and the importance of volunteers in making this happen: "The official message which came over was in a context of what was given was great. It gave you a taste of what was to come. When they showed you the closing ceremony of Kuala Lumpur I thought WOW" (younger male, employed, no previous volunteering experience).

It had been very effective in boosting morale and team spirit. It also served some purpose of training and communication, as one participant commented: "the message had obviously got through. Even on the way home on the Metro, there was a little old lady trying to get out of the door and seven people jumped up to help her to show that they'd learned to be a volunteer" (younger male, employed, previous volunteering experience).

The discussion referred to recruitment processes. Participants were asked whether or not they had a preference for a specific job or role when they applied to be a volunteer and whether or not this preference had been met. Once again there were mixed experiences. Some people had applied for a specific role either because they had an interest in that sport or to develop skills that were beneficial to their career. They were disappointed that they were not offered their preferred job. One recurring major criticism raised by participants related to the assessment of their skills. They argued that previous experience and particular skills were rarely taken into account during the recruitment process. They felt this was surprising and disappointing, especially so with the length of the application form and the amount of detail they were required to provide. They were also disappointed that some of them had been interviewed by other long-term volunteers rather than professional interviewers. For the majority the underlying principle, however, was to be involved in the Games and they had no particular preference for what job they would be allocated. The allocation of jobs satisfied this desire and for some their role far exceeded what they had expected. The range of jobs allocated was extensive as were the venue allocations in Manchester and the North West of the UK.

Expectations regarding training were also mixed. Many had not received any formal training by the time of the focus groups and were concerned that this was too late in the process. Of those who had been trained the overall view was that the training sessions and venue tours were of a high quality: "I've been really impressed with the people running the ceremonies. They understand that you won't be perfect at this stage but that it's progressive. If you should be from 1-12, then now you'll be at 3 but next time you'll be a 5. It's building your confidence as you go along" (younger male, employed, previous volunteering experience). 
On the negative side, a number of participants complained about the lack of organization or planning of the training. This was an expression of a serious criticism, especially as several people had been frustrated by the way in which training sessions had been cancelled at very short notice. They felt this was discourteous and unprofessional and made people unsure about other aspects of the Games. While there were no concerns regarding the content of the training sessions, a small minority of participants felt that some of the trainers lacked enthusiasm. However, this topic evoked opposing views. Some commented that the trainers were "red hot," although there were some reservations about the style of training, which they considered to be very unsophisticated in its approach. In summary, the overall impression from the Groups was that the training sessions had worked well and volunteers were valued throughout the program:

I have to say that every letter that I have received, and I have had an awful lot of them, that they've made me feel as though I am special and everyone is so appreciative of what you do. You are a volunteer and they are delighted that you are part of the team. (older male, retired, previous volunteering experience).

Yesterday, I went to the training for the opening ceremony and it was our first one and we met up with the other people there. They made a big fuss of us, this is their first time, and please look after them, take care of them. I thought it was ... you just feel very special. It is a lovely way because a lot of volunteering you do you are just an also ran, they do it, you are forgotten, etc but I find that with these people they have been wonderful. You cannot fault it in any way. (older male, employed, previous volunteering experience)

One area where expectations had clearly not been met was with regard to communication, especially between the management and volunteers prior to the Games. Many participants felt that communication about recruitment and training had been erratic. There was a feeling that there was a lack of planning, which led to everything being organized or communicated at the last minute. This was unsatisfactory because they had to plan their work arrangements, family commitments, and holidays way in advance of the Games. The perceived lack of communication generated an apprehension amongst volunteers about other dimensions of the Games. For example, several people were concerned about transport arrangements and indicated that they would drop out if they were not supplied with travel details in the near future.

Group members were asked about their expectations regarding the event itself. They were invited to comment about what they now expected (i.e., what would be the high and low points of working as a volunteer during the Games). Many felt that the high points would relate to the sporting nature of the event, the teamwork, and comradeship, which would make the Games a success: “There's one key factor in it all—it's sport ... . and once you get talking to people it's incredible how much they will open up. It is being friendly, it is being nice to people that help you through the rough patches" (older male, employed, previous volunteering experience).

They welcomed the idea of meeting a wide range of people, in particular the cultural diversity and being with athletes from all over the world. There was also a matter of pride; this was a major factor for many. Volunteers would only be satisfied if Manchester gained recognition as a place fit to hold the Games as well as being an exciting place to be: "It's the fact that all these people are coming to look at Manchester. I want them to look at Manchester and think what a great place that is, and they will have met us all and seen what we have to offer them" (older male, employed, no previous volunteering experience).

The low points tended to be expressed as concerns about transport, especially in relation to early morning shifts and personal security late at night. Another major problem they foresaw was a continued lack of communication between management and volunteers. Finally, they anticipated that they would be very tired after finishing a series of long shifts, especially older members of the volunteer program: "I know that I am starting at seven o'clock in the morning until four o'clock in the afternoon. I am going to be pretty knackered . . . if I am on my feet all day shepherding people around the stadium . . . highlight, the highlight is going home" (older male, retired, previous volunteering experience).

There were a few other minor considerations. A small number of participants thought that it might be very boring at times. Others commented that it could be very frustrating if visitors were not satisfied through having to queue for security checks, etc. A few people in one group were concerned about there not being a sufficiently balanced racial mix, especially from Asian groups. Almost all participants indicated that whatever the problems they would continue as a volunteer 
throughout the entire Games. They would endure the rough with the smooth to make the Games a success.

The discussion concluded on their expectations about the long-term impacts of the Games on Manchester. All groups considered that Manchester would gain substantially from the Games in terms of infrastructure and regeneration. The sporting legacy was considered to be particularly important with the provision of stadiums and venues that could be used to good effect afterwards. It was appreciated that it would take time to gain a return on the investment but the Games would be worthwhile. It would enhance the opportunities for Manchester to bid for other major international events and would also be of benefit to residents in some instances. The participants also appreciated how important it was for Manchester to improve its image; they were conscious that Manchester needed to prove itself as a destination.

Finally, participants were asked whether they would be interested in volunteering for other events in the future. Responses were circumspect. Many commented that it would depend on the nature of the experience. Some of the younger participants were sufficiently encouraged to make enquiries about future opportunities, such as the next Commonwealth Games to be hosted by Melbourne.

\section{Implications}

The focus group discussions verify the work of previous studies in that volunteers were motivated primarily by three factors:

- $\quad$ altruism (i.e., wishing to give something back to society as well as in some cases sport or in other cases to Manchester);

- involvement (i.e., wanting to feel useful, to be respected for their work and their role, to be part of a team);

- the uniqueness of the Games and being part of this rather special event.

Thus, in terms of recruitment, training, and formulating expectations, these motivation factors are more important than other elements. Once recruited, volunteers' aspirations and commitment to the event are affirmed through their desire to develop a working relationship with management, which is reflected in the psychological contract. Management can harness this positive energy force in a number of ways, especially in the early anticipatory socialization stage, by involving volunteers at orientation, induction, and training sessions at regular intervals prior to the event. However, what emerges from the group discussion is a common desire for preplanning and the provision of long time leads in the communication process simply because volunteers are fitting this into an established pattern of life. For example, taking leave from work or making family arrangements requires consultation over a period of time. Thus, for volunteers the contract begins when the application form is accepted, way in advance of the event; they expect to be managed and valued from then onwards.

In terms of expectations, a number of key issues were identified in relation to recruitment, training, and other management dimensions of the Games. Volunteers considered that to be successful an event should be well planned and the countdown period managed effectively. There were mixed opinions regarding the administration of recruitment and training prior to the Games. The main reservation was in relation to the recruitment process; many felt that there was an inadequate assessment of skills and hence volunteers would not be used to good effect. However, most considered that the training was of a high standard, and that there was developing a positive noncomplaining, friendly attitude towards and between volunteers. On the whole, volunteers felt welcome and much appreciated by the management team during this induction process. This helped to strengthen their affinity to the team and the event itself. In relation to communication between the management team and volunteers, there was a feeling, prior to the Games, that this could have been much better. For example, there were real anxieties about how volunteers would travel to their venues. The management team had not issued briefing information in advance and some volunteers withdrew because they did not feel the transport system would work properly for them to undertake early and late shifts at venues. Failure to recognize early negative aspects and volunteers' concerns was in danger of jeopardizing the positive relationships that was developing in other areas.

With regard to expectations about how things would be during the Games, the volunteers felt that there would be day-to-day problems and some felt that visitors would not respect them. Regardless of these doubts, the respondents clearly had an expectation that overall it would be a good experience and the event would be a real success. Their main aim was to bring pride to the 
event through management and volunteers working together, and they were prepared to accept minor breaches of the psychological contract in the pursuit of this aim. In sum, they felt that being involved and helping to generate a special atmosphere would far outweigh the dis-benefits incurred. They also seemed to have a degree of optimism regarding the long-term outcomes of the Games and their propensity to volunteer again in the future.

In summing up, group members were asked in one word or phrase what being a volunteer at the Games meant to them. Most people were optimistic regarding their expected experience; it would be a unique event and a chance of a lifetime to be involved:

Inspiration. We'll never be able to repeat this experience and feeling. Even if we had the Games again in Manchester they'll never be anything like the first time. Its like going on holiday for the first time. When you go back there you can't compare the same place or time. It's the people who you meet and what you put in. You can never relive the same experiences twice. It's going to be an inspiration for us all. (younger female, unemployed, previous volunteering experience)

\section{Conclusions}

There are a number of common themes and management implications stemming from the interpretation of these findings and in light of the previous literature. Firstly, the nature and the reasons associated with the expectations about the event were similar across the groups and regardless of composition. The limitations expressed earlier in this article with regard to focus group technique and that the analysis is based on seven groups only means that it is not possible to develop a model at this stage of the research. However, there are a number of conclusions that can be drawn.

First, it seems that regardless of previous experience, volunteer background, and reason for participating, volunteers are seeking fulfillment of a psychological contract from the outset and not simply during the period of volunteer engagement during the event. As the early stages of the psychological contract are based largely on trust, then any early contact or activities are essential in validating this trust that expectations will be fulfilled. In this case, the welcome afforded to all volunteers had an impact on expectations.

Secondly, there appears to be an ideal set of expected outcomes regarding planning, recruitment, training, and communications but also a realism that expectations are not always met. Thus, there appears to be a degree of compensation afforded in circumstances where expectations are met but barely. However, it is clear that if expectations are not met with a degree of adequacy then the level of concern and in some cases withdrawal from the process can be expected. This happened for many volunteers in relation to the lack of communication between management and volunteers and in relation to transport. There is a fine line between perceptions of breach of the psychological contract and violation. Although some volunteers have more tolerance of uncertainty and unmet expectations, it would be unwise for management to become complacent. The desire to be part of a special or unique event may attract volunteers in the first place, but it may not be strong enough to influence their attitudinal or behavioral responses to management reneging on expectations and perceived promises.

The third key issue the research raises is that such events seem to arouse optimism and positive word-ofmouth marketing not at a level expected given the perceived lack of planning. This optimism extended into expectations regarding long-term outcomes. Thus, if effectively managed volunteers can generate a positive wave of expectation and citizenship in the period leading up to the Games. The challenge is for managers to plan these outcomes well in advance of such an event to reap the benefits of a highly charged, if temporal, volunteer workforce.

The aim of the researchers will be to reconvene the focus groups in the near future to develop a longitudinal study of attitudes towards volunteering and other tourism-related events in Manchester. In this way it will be worthwhile to report in the future on how the expectations of the groups have changed postevent.

\section{References}

Anderson, J., \& Moore, L. (1978). The motivation to volunteer. Journal of Voluntary Action Research, 7, 51-60.

Blaikie, N. (2000). Designing social research. Cambridge: Polity Press.

Bretell, D. (2000). Sydney Olympic and Paralympic Games. In M. Moragas, A. Moreno, \& N. Puig (Eds.), Symposium on volunteers, global society and the Olympic movement (pp. 133-155). Lausanne, November 24-26, 1999, International Olympic Committee.

Burns, L. (2000). European Volunteer Centre. In M. Moragas, A. Moreno, \& N. Puig (Eds.), Symposium on volunteers, global society and the Olympic movement (pp. 55-58). Lausanne, November 24-26, 1999. International Olympic Committee. 
Burns, J., Hatch, J., \& Mules, T. J. (Eds.). (1986). The Adelaide Grand Prix: The impact of a special event. Adelaide: The Centre for South Australian Economic Studies.

Caldwell, L., \& Andereck, K. (1994). Motives for initiating and continuing membership in a recreation-related voluntary association. Leisure Studies, 16, 33-44.

Catterall, M., \& Maclaran, P. (1997). Focus group data and quantitative analysis programs: Coding and moving pictures as well as the snapshots. Sociological Research Online, 2(1). http:www.socresonline.org.uk/socresonline/2/1/6.html

Chalip, L. (2000). Sydney 2000: Volunteers and the organisation of the Olympic Games: Economic and formative aspects. In M. Moragas, A. Moreno, \& N. Puig (Eds.), Symposium on volunteers, global society and the Olympic movement (pp. 205-214). Lausanne, November 24-26, 1999, International Olympic Committee.

Clary, E., \& Snyder, M. (1999). The motivations to volunteer: Theoretical and practical considerations. Current Directions in Psychological Science, 8, 156-159.

Clary, E., \& Snyder, M. (2000, February). Why do people volunteer? Understanding volunteer motivations. The Not-forProfit CEO Monthly Letter, 7, 3-5.

Clary, E., Snyder, M., Ridge, R., Copeland, J., Stukas, A., Haugen, J., \& Miene, P. (1998). Understanding and assessing the motivations of volunteers: A functional approach. Journal of Personality and Social Psychology, 74, 1516-1530.

Coyle-Shapiro, J. (2002). The psychological contract perspective on organizational citizenship behaviour. Journal of Organisational Behaviour, 23, 927-946.

Coyle-Shapiro, J., \& Kessler, I. (2000). The consequences of the psychological contract: A large scale survey. The Journal of Management Studies, 37, 904-930.

Coyne, B., \& Coyne, J., Sr. (2001). Getting, keeping and caring for unpaid volunteers at professional golf tournament events. Human Resource Development International, 4(2), 199-214.

Crabtree, B. F., \& Miller, W. L. (1999). Using codes and code manuals: A template organising style of interpretation. In B. F. Crabtree \& W. L. Miller (Eds.), Doing qualitative research (2nd ed., pp. 163-177). London: Sage.

Davis Smith, J. (1998). The 1997 National Survey of Volunteering. London. The National Centre for Volunteering.

Dean, L. (1985). Learning about volunteer burnout. London: Voluntary Action Leadership.

Elstad, B. (1997). Volunteer perception of learning and satisfaction in a mega-event: The case of the XV11 Olympic Winter Games in Lillehammer. Festival Management \& Event Tourism, 4, 75-83.

Elstad, B. (2003). Continuance commitment and reasons to quit: A study of volunteers at a jazz festival. Event Management, 8, 99-108.

Farmer, S. M., \& Fedor, D. B. (1999). Volunteer participation and withdrawal: A psychological contract perspective on the role of expectations and organisational support. Nonprofit Management and Leadership, 9, 349-367.

Farmer, S. M., \& Fedor, D. B. (2001). Changing the focus on volunteering: An investigation of volunteers' multiple contributions to a charitable organisation. Journal of Management, 27(2), 191-211.
Farrell, J., Johnston, M., \& Twynam, G. (1998). Volunteer motivation, satisfaction and management at an elite sporting competition. Journal of Sport Management, 12, 288-300.

Frey, J. H., \& Fontana, A. (1993). The group interview in social research. In D. L. Morgan (Ed.), Successful focus groups: advancing the state of the art (pp. 20-34). Newbury Park: Sage.

Galindo-Kuhn, R., \& Guzley, R. (2001). The Volunteer Satisfaction Index: Construct definition, measurement, development and validation. Journal of Social Science Research, 28(1), 45-68.

Garavan, T., \& Morley, M. (1997). The socialisation of highpotential graduates into the organization, initial expectations, experiences and outcomes. Journal of Managerial Psychology, 12(2), 118-137.

Getz, D. (1989). Festival and special event sponsorship: A systems approach. Paper presented to the Travel and Tourism Research Association, Honolulu.

Getz, D. (1991). Festivals, special events and tourism. New York: Van Nostrand Reinhold.

Getz, D. (1997). Event management \& event tourism. New York: Cognizant Communications Corporation.

Gidron, B. (1983). Sources of job satisfaction among service volunteers. Journal of Volunatry Action Research, 12, 20-35.

Goodlad, S., \& McIvor, S. (1998). Museum volunteers: Good practice in the management of volunteers. London: Routledge.

Goss, J. D. (1996). Focus groups as alternative research practice: Experience with transmigrants in Indonesia. Area, 28(2), 115-123.

Grant, D. (1999). HRM, rhetoric and the psychological contract: A case of "easier said than done." International Journal of Human Resource Management, 10(2), 327-350.

Gratton, C., Dobson, N., \& Shibly, S (2000). The economic importance of major sports events: A case-study of six events. Managing Leisure, 5, 17-28.

Greenbaum, T. L. (2000). Moderating focus groups: A practical guide for group facilitation. Thousand Oaks, CA: Sage.

Gronroos, C. (1982). Strategic management and marketing in the service sector. Helsingfor: Swedish School of Economics and Business Administration.

Heindrich, K. (1990). Working with volunteers in employee services and recreation programmes. Champaign, IL: Sagamore.

Hirst, A. (2000). Links between volunteering and employability (Research Report RR 309). Department for Education and Skills.

Holbrook, B. (1996). Shopping around: Focus group research in North London. Area, 28(2), 136-142.

Hollway, S. (2001). Enduring benefits of the Olympic Games for Australia. Olympic Review, 27(38), 28-33.

Holmes, K. (1999). Changing times: Volunteering in the heritage sector 1984-1998. Voluntary Action, 1(2), 21-35.

Howell, A. (1986). Why do volunteers burnout or dropout? Volunteers \& volunteerism in Calgary series. No. 8. Research unit for public policy studies. University of Calgary.

Kay, S. (1997). From charismatic explorer to settler: A new perspective on volunteering in the arts in the UK. Proceedings of the 4th International Arts and Cultural Management 
(AIMAC) Conference (pp. 1-19). Golden Gate University.

Kemp, S. (2002). The hidden workforce: Volunteers' learning in the Olympics. Journal of European Industrial Training, 26(2/ 3/4), 109-116.

Kreuger, R. A. (1988). Focus groups: A practical guide for applied research. Newbury Park: Sage.

Kreuger, R. (1998). Involving community members in focus groups. London: Sage.

Lord, B., \& Lord, G. (1997). The manual of museum management. The Stationery Office.

MacAloon, J. (2000). Volunteers, global society and the Olympic movement. In M. Moragas, A. Moreno, \& N. Puig (Eds.), Symposium on volunteers, global society and the Olympic movement (pp. 17-29). Lausanne, November 24-26, 1999, International Olympic Committee.

Mattingly, J. (1984). Volunteers in museums and art galleries: The report of a survey into the work of volunteers in museums and galleries in the United Kingdom. London: The Volunteer Centre.

Miller, L. (1985). Understanding the motivation of volunteers: An examination of personality differences and characteristics of volunteers in paid employment. Journal of Voluntary Action Research, 14(1), 112-122.

Moragas, M., Moreno, A., \& Paniagua, R. (2000). The evolution of volunteers at the Olympic Games. In M. Moragas, A. Moreno, \& N. Puig (Eds.), Symposium on volunteers, global society and the Olympic movement (pp. 133-155). Lausanne, November 24-26, 1999, International Olympic Committee.

Morrison, S., \& Robinson, S. (1997). When employees feel betrayed: A model of how psychological contract violation develops. Academy of Management Review, 22(1), 225-256.

Mules, T., \& Faulkner, B. (1996). An economic perspective on special events. Tourism Economics, 2(2), 107-117.

Nakajima, S. (2000). Nagano '98. Activist volunteering: The Bind-Aid Group and its work prior to the Nagano Games. In M. Moragas, A. Moreno, \& N. Puig (Eds.), Symposium on volunteers, global society and the Olympic movement (pp. 187-190). Lausanne, November 24-26, 1999, International Olympic Committee.

Pate, J., \& Malone, C. (2000). Post 'psychological contract' violation: The durability and transferability of employee perceptions. European Journal of Industrial Training, 24(2/3/ 4), 158-166.

Pate, J., Martin, J., \& McGoldrick, J. (2003). The impact of psychological contract violation on employee attitudes and behaviour. Employee Relations, 25(6), 557-573.

Pearce, J. (1993). Volunteers: The organisational behaviour of unpaid workers. London: Routledge.

Porter, L., \& Lawler, E. (1968). Managerial attitudes and performance. Homewood, IL: Irwin.

Porter, M. (1980). Competitive strategy. New York: The Free Press.
Ritchie, J. R. B., \& Aitken, C. E. (1984). Assessing the impacts of the 1988 Olympic Winter Games: The research program and initial results. Journal of Travel Research, 22(3), 17-25.

Robinson, S., \& Morrison, E. (1995). Psychological contracts and OCB: The effect of unfulfilled obligations on civic virtue behaviour. Journal of Organisational Behaviour, 16(3), 289-298.

Robinson, S., \& Rouseau, D. (1994). Violating the psychological contract: Not the exception but the norm. Journal of Organisational Behaviour, 15(3), 245-259.

Ronningen, P. (2000). Lillehammer '94. In M. Moragas, A. Moreno, \& N. Puig (Eds.), Symposium on volunteers, global society and the Olympic movement (pp. 183-186). Lausanne, November 24-26, 1999, International Olympic Committee.

Rouseau, D. (1989). Psychological and implied contracts in organisations. Employee Responsibilities and Rights Journal, 2(2), 121-139.

Rousseau, D. (1995). Psychological contracts in organisations: Understanding the written and unwritten agreements. London: Sage.

Rouseau, D., \& Parks, J. (1993). The contracts of individuals and organizations. In L. Cummings \& B. Staw (Eds.), Research in organisational behaviour. Greenwich, CT: JAI Press.

Scolarios, D., Lockyer, C., \& Johnson, H. (2003). Anticipatory socialization: The effect of recruitment and selection experiences on career expectations. Career Development International, 28(4), 182-197.

Smith, K. (2002). Modelling the volunteer experience: findings from the heritage centre. Voluntary Action, 4(2).

Strauss, A. L. (1987). Qualitative analysis for social scientists. Cambridge: Cambridge University Press.

Unger, L (1991). Altruism as a motivation to volunteer. Journal of Economic Psychology, 12, 71-100.

Van Maanen, J., \& Schein, E. (1979). Towards a theory of organsational socialization. In B. Straw (Ed.), Research in organisational behaviour (Vol. 1, pp. 209-264). Greenwich, CT: JAI Press.

Vroom, V. (1964). Work and motivation. Chichester: Wiley.

Wardell, F., Lishman, J., \& Whalley, L. (2000). Who volunteers? British Journal of Social Work, 30, 227-248.

Williams, P., \& Harrison, L. (1988). A framework for marketing ethnocultural communities and festivals. Unpublished report to the Secretary of State Mulitculturalism. Ottawa: Secretary of State.

Williams, P., Dossa, K., \& Tompkins, L. (1995). Volunteerism and special event management: A case study of Whistler's Men's World Cup of Skiing. Festival Management \& Event Tourism, 3, 83-95.

Zeithaml, V., Berry, L., \& Parasuraman, A. (1988). Communication and control processes in the delivery of service quality. Journal of Marketing Management, 52, 35-48. 